\title{
Pigment and Ink Analysis of Medieval Books through Complementary Spectroscopy Techniques
}

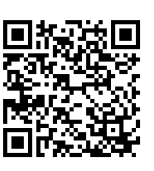

\author{
Khachatur V Manukyan ${ }^{1}$, Mark Raddell ${ }^{1}$, Erica Sestak ${ }^{2}$, David T Gura ${ }^{3}$, Zachary D Schultz ${ }^{4}$, and Michael \\ Wiescher ${ }^{1 *}$ \\ ${ }^{1}$ Nuclear Science Laboratory, Department of Physics, University of Notre Dame, USA
}

${ }^{2}$ Medieval Institute, College of Arts \& Letters, University of Notre Dame, USA

${ }^{3}$ Hesburgh Library, University of Notre Dame, USA

${ }^{4}$ Department of Chemistry and Biochemistry, University of Notre Dame, USA

Submission: December 15, 2017; Published: April 19, 2018

*Corresponding author: Michael Wiescher, Nuclear Science Laboratory, Department of Physics, University of Notre Dame, Notre Dame, IN 46556, USA, Tel:(574) 631-6788; Fax: (574) 631-5952; Email: mwiesche@nd.edu

\begin{abstract}
The complementary applications of X-ray Fluorescence and Raman Spectroscopy open new possibilities for revealing valuable historical information regarding preparation methods and human activities during the creation of artistic or archaeological objects. We report on an approach combining X-ray Fluorescence mapping with Raman Spectroscopy to identify the elemental and molecular makeup of inks and pigments in three fifteenth-century European medieval manuscripts held in the University of Notre Dame's Rare Books and Special Collections. This combination of atomic and molecular spectroscopic techniques provides in-depth characterizations of the manuscripts in question. Our results suggest that discovering significant differences in the trace elements composing inks and pigments could open anew avenue for linking different manuscripts that share a common origin and provenance. The combined application of these two tools could also generate valuable knowledge of labor distribution during the preparation of manuscripts.
\end{abstract}

Keywords: X-ray fluorescence; Raman spectroscopy; Medieval manuscript; Pigment; Inks

Abbreviations: XRF: X-ray fluorescence; RS: Raman spectroscopy; EDAX: Orbis XRF device

\section{Opinion}

Spectroscopic and other scientific methods have long been employed to explore materials used for art and archaeological objects [1-6]. The knowledge of the composition and degradation of such objects is critical for conservation and restoration efforts. Modern scientific methods could help in determining not only materials makeup but also in unveiling valuable historical information on preparation methods as well as human activities during the creation of artistic or archaeological objects. The indepth analysis could reveal relevant information on unknown trade routes for raw materials which were used for the preparation of these objects. Scientific characterization of such materials requires the utilization of non-destructive analytical tools. Several well-known methods, such as X-ray fluorescence (XRF) and Raman spectroscopy (RS), are widely used to determine the elemental and chemical compositions of art and archaeological materials [7-12].
XRF utilizes high-energy X-rays that excite core electrons of the atoms in materials. The unstable ionized atoms then return to the ground state by series of electronic transitions in the lower orbitals emitting characteristic X-rays. Analyzing these characteristic X-rays determines the elemental makeup of materials. XRF also enables the detection of elements with trace concentrations in multi-elemental objects. However, XRF cannot be used for measuring the lighter elements (e.g., hydrogen, oxygen, carbon, nitrogen).

RS investigates the inelastic scattering of monochromatic light (i.e. laser) during its interaction with materials. While interacting with vibrations, phonons or other excitations in the materials the light scatters resulting in the energy shift of the photons. RS provides the molecular identity of materials, but it is a localized technique, and the distribution of compounds in large areas through mapping is difficult to obtain. Therefore, the coupling of XRF and RS can overcome the limitations of 
individual techniques and increase information gathered from the analysis $[7,11,13,14]$.

Here, we combine XRF elemental mapping with RS to identify the elemental and molecular compositions of inks and pigments in three fifteenth-century European medieval manuscripts held in the University of Notre Dame's Hesburgh Library [15]. An Orbis XRF device (EDAX) with a ruthenium X-ray tube was utilized for elemental analysis. Orbis is equipt with poly-capillary optics which enable the production of a focused X-ray beam with a spot size of $\sim 30 \mu \mathrm{m}$. This feature coupled with a sample stage, along with an automated XYZ positioner, generates elemental distribution maps from a reasonably large sample. RS was conducted by an in Via Raman Microscope equipped with a He Ne laser operating at $\sim 633 \mathrm{~nm}$. The laser beam was focused with a50x objective lens to realize a spatial resolution of $\sim 2 \mu \mathrm{m}$. The laser power was kept below one milliwattto prevent possible degradation of the manuscripts.

Figure 1 displays a set of results obtained by XRF elemental mapping and RS. The maps illustrate that the white areas in this particular illumination contain lead (Figure 1A). Raman spectrum taken from white areas (Figure 1B) exhibit an instance band for $2 \mathrm{PbCO}_{3} \bullet \mathrm{Pb}(\mathrm{OH})_{2}$ (white lead) pigment [9]. XRF mapping of the red area reveals an association with mercury and lead. Raman spectroscopy (Figure 3C)of the red area suggests a mix of two red pigments: red lead $\left(\mathrm{Pb}_{3} \mathrm{O}_{4}\right)$ and vermilion ( $\left.\mathrm{HgS}\right)$ [9]. It can be seen that the intensities of vermilion bands are significantly higher than those of the red lead. The XRF analysis indicates the opposite result, in which the concentration of lead is nearly five times greater than mercury found in the same area. We used the depth-profiling feature of Raman spectroscopy to understand these results. Figure 1D presents the depth profiles of the vermilion band centered at $251 \mathrm{~cm}^{-1}$ and the red lead band at $118 \mathrm{~cm}^{-1}$ through the layer of paint, as well as the $\mathrm{HgS}$ / $\mathrm{Pb}_{3} \mathrm{O}_{4}$ intensity ratio for these bands. Based on these results, we conclude that the surface layer of the paint, with a thickness of $\sim 150 \mu \mathrm{m}$, contains more vermilion, and that its concentration gradually decreases within that layer. The $\mathrm{HgS} / \mathrm{Pb}_{3} \mathrm{O}_{4}$ ratio in the second layer, -150 to $-600 \mu \mathrm{m}$, is smaller. These qualitative results may indicate that the red area was painted with red lead, and a vermilion-rich layer was applied as a glaze. We can suggest two possible explanations for the use of such composite red colorant. First, it is possible that the artist used doublelayer painting to achieve a distinctive shade of red color. Second, vermilion was an expensive pigment in comparison to red lead. Therefore, the artist probably first painted a thicker layer of $\mathrm{Pb}_{3} \mathrm{O}_{4}$, followed by an application of a thin layer of $\mathrm{HgS}$.
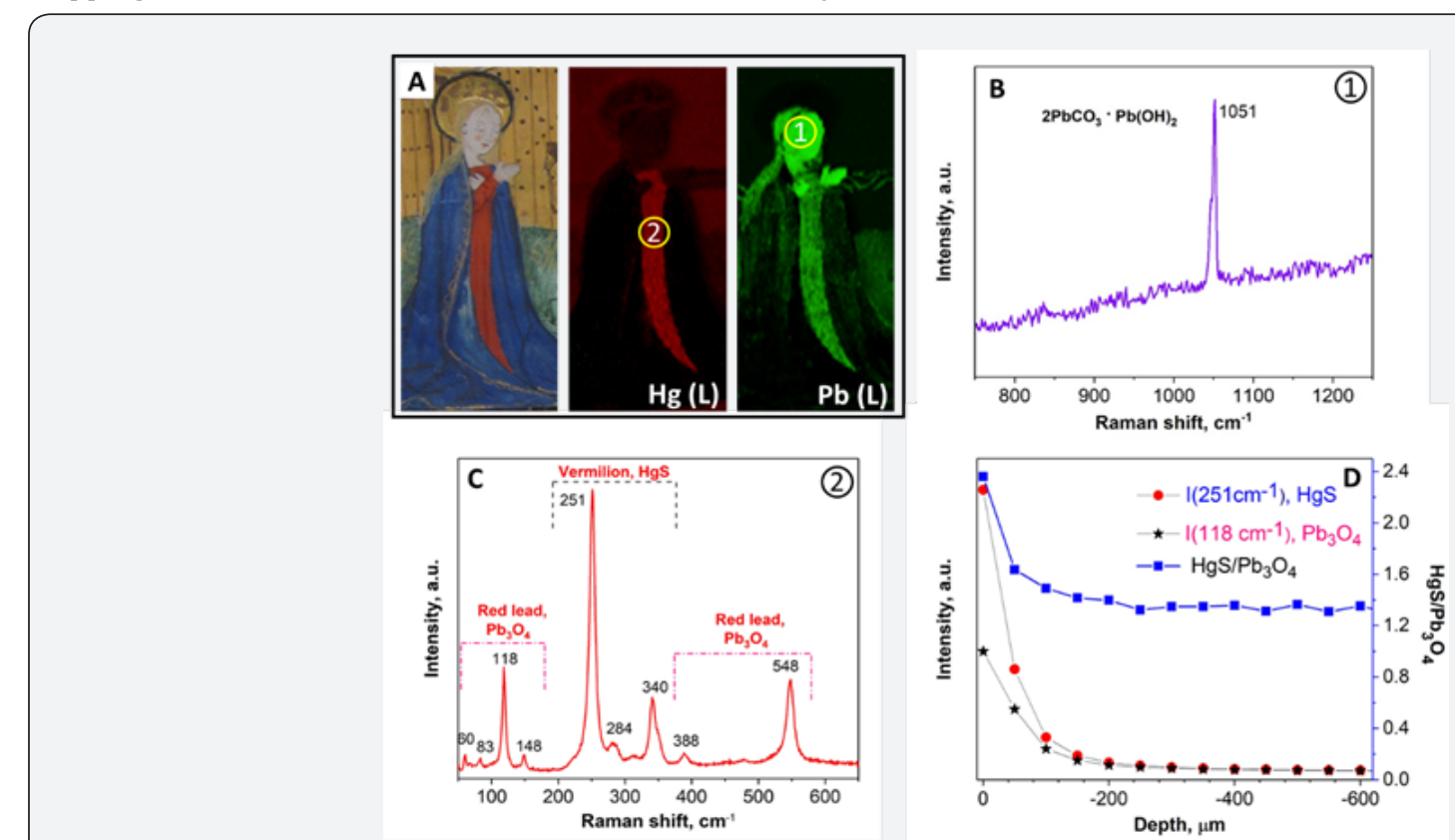

Figure 1: Distribution of metals (A) in a leaveof Frag. III. 1, f. 89r. Book of hours, use of Vannes. Brittany, France, ca. 1450 AD, Raman spectra for white (B) and red areas (C), as well as depth profile results (D) for $\mathrm{HgS}$ and Pb3O4 in the red area.

Such combinations of vermilion and red lead pigment also can be seen in the texts of manuscripts. Figure 2A shows that the red area contains mercury and sulfur (vermilion) as well as lead (red lead). Another significant finding is that the black inks used in these manuscripts show significant differences in their elemental compositions. For example, Figure 2A presents black ink that contains $\mathrm{Fe}, \mathrm{S}, \mathrm{Cu}$, and $\mathrm{Zn}$. Iron-based inks were primarily used in medieval manuscripts. These inks were prepared by adding ground melanterite mineral $\left(\mathrm{FeSO}_{4} \cdot 7 \mathrm{H}_{2} \mathrm{O}\right)$ to a solution of gallotannic acid extracted from oak trees. Melanterite always contains some impurity elements such as zinc, gold, aluminum, copper, etc [16]. Indeed, as mentioned above, Figure 2A shows the presence of copper and zinc. It is also possible that pigments containing copper were deliberately added to iron gall inks to obtain different shades. Unfortunately, we were unable to obtain Raman spectra from those inks due to the significantly high 
fluorescent background. Figure 2A shows, however, a blue area, which was identified as azurite $\left(2 \mathrm{CuCO}_{3} \bullet \mathrm{Cu}(\mathrm{OH})_{2}\right)$ by $\mathrm{RS}$ (not shown). We can assume that the artist mixed the same azurite pigment with iron gall ink to adjust its color.

Another set of XRF mapping results shows that the black ink found in different manuscript contains $\mathrm{Fe}, \mathrm{S}, \mathrm{Zn}$ and Sn (Figure 2B). Here it is possible that tin was found as an impurity in an initial melanterite mineral or it was incorporated during the processing of the ore. XRF mapping also evidences that this ink has no copper. Areas that show a significant amount of copper are associated with illustrated initials. They also shine from the back side of the leave.

Figure 2 Distribution of metals in leaves of two different manuscripts:(A) cod. Lat. b. 2, (7v folio). Dominican Psalter. Germany, ca. 1400-1450 with additions after 1456; (B) cod. Lat. a. 6 (92 folio). Book of hours, Use of Rome. Bruges, ca. 14501500 .

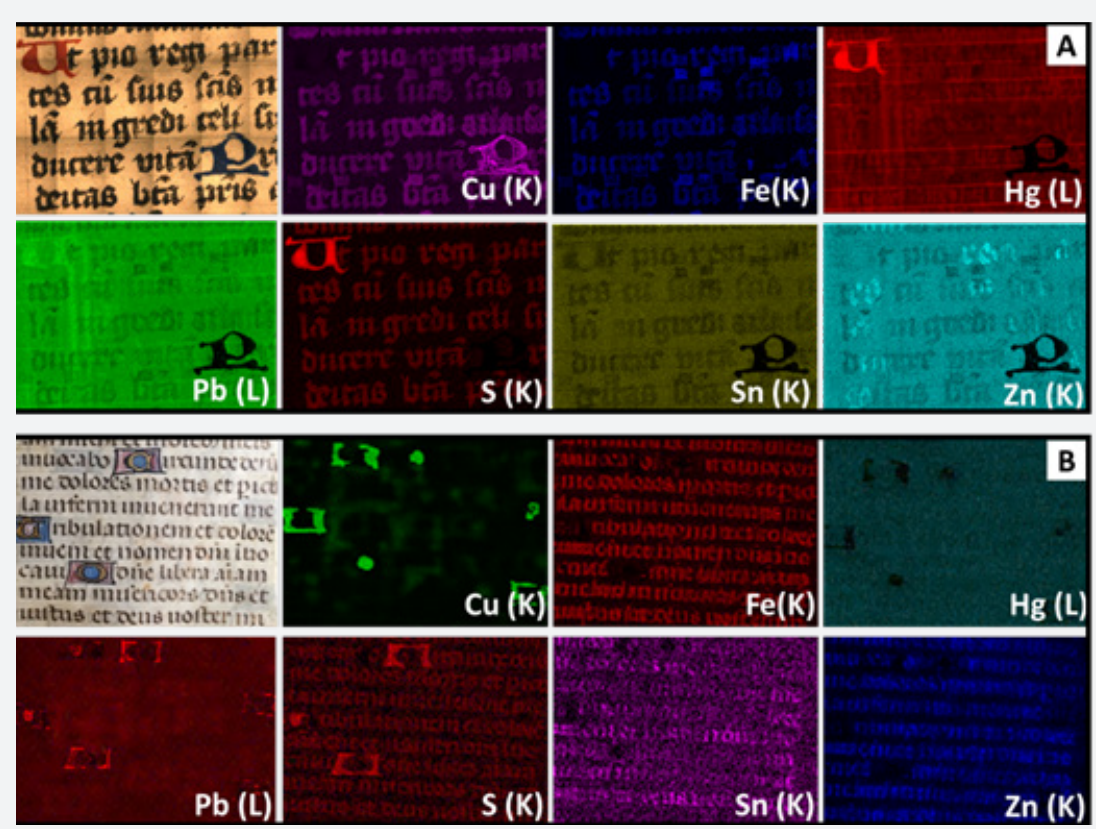

Figure 2: Distribution of metals in leaves of two different manuscripts:(A) cod. Lat. b. 2, (7v folio). Dominican Psalter. Germany, ca. 14001450 with additions after 1456; (B) cod. Lat. a. 6 (92 folio). Book of hours, Use of Rome. Bruges, ca. 1450-1500.

Such significant differences in the trace elements found in inks create new opportunities to link specific manuscripts that might share a common origin. This approach might also provide insights into the processes that were involved in the preparation of the manuscripts. This reflects directly on the origin and provenance of the manuscripts and their authenticity. The analysis of inks and pigments in illuminations could furnish a new view of workshop practices. Often teams of different artists, scribes, associates, and apprentices were responsible for the production of one manuscript. In some cases, illuminations were made in one location and exported to another to be inserted into locally produced manuscripts. The combined application of XRF and RS can shed light on labor distribution during the preparation of manuscripts. However, the lack of standard materials and the different thicknesses of paint layers makes it difficult for a precise quantification of the element content in the manuscripts.

\section{Conclusion}

This combination of atomic and molecular spectroscopic techniques provides an in-depth characterization of the pigments and inks used in the preparation of the medieval manuscript. Our results suggest that a significant difference between trace elements found in inks and pigments could open a new avenue for linking different manuscripts that might share a common origin and/or provenance. The combined application of these two tools potentially could generate valuable knowledge on labor distribution during the preparation of manuscripts.

\section{Acknowledgment}

This research was partially supported by Faculty Research Support Regular Grant program of the University of Notre Dame. E. Sestak also acknowledges support from The Da Vinci Summer Grant Program of the University of Notre Dame. Mark Raddell also acknowledges Undergraduate Research Support Program from College of Science, University of Notre Dame.

\section{References}

1. Artioli G (2010) Scientific Methods and Cultural Heritage: An introduction to the application of materials science to archaeometry and conservation science. Oxford University Press, Oxford, UK, pp. $1-536$.

2. Janssens K, Dik J, Cotte M, Susini J (2010) Photon-based techniques for non destructive subsurface analysis of painted cultural heritage artifacts. Acc Chem Res 43: 814-825. 
3. Howard DL, de Jonge MD, Lau D, Hay D, Varcoe-Cocks M, et al. (2012) High-definition X-ray fluorescence elemental mapping of paintings. Anal Chem 84: 3278-3286.

4. Salvadó N, Butí S, Aranda MAG, Pradell T (2014) New insights on blue pigments used in 15th century paintings by synchrotron radiationbased micro-FTIR and XRD. Anal Methods 6: 3610-3621.

5. de Viguerie L, Walter P, Laval E, Mottin B, Solé VA (2010) Revealing the sfumato technique of Leonardo da Vinci by X-ray fluorescence spectroscopy. Angew Chemie 49: 6125-6128.

6. Thurrowgood D, Patersonn D, de Jonge MD, Kirkham R, Thurrowgood S, et al. (2016) A Hidden Portrait by Edgar Degas. Sci Rep 6: 1-10.

7. Paternoster G, Rinzivillo R, Nunziata F, Castellucci EM, Lofrumento C, et al. (2005) Study on the technique of the Roman age mural paintings by micro-XRF withPolycapillary Conic Collimator and micro-Raman analyses. J Cult Herit 6: 21-28.

8. Angelici D, Borghi A, Chiarelli F, Cossio R, Garianietal G (2015) $\mu$-XRF analysis of trace elements in lapis lazuli-forming minerals for a provenance study. Microsc Microanal 21: 526-533.

9. Burgio L, Clark RJH (2001) Library of FT-Raman spectra of pigments, minerals, pigment media and varnishes, and supplement to existing library of Raman spectra of pigments with visible excitation. Spectrochim Acta A 57: 1491-1521.

This work is licensed under Creative Commons Attribution 4.0 License DOI: 10.19080/GJAA.2018.03.555619
10. Ruberto C, Mazzinghi A, Massi M, Castelli L, Czelusniak C, et al. (2016) Imaging study of Raffaello's “La Muta” by a portable XRF spectrometer. Microchem J. 126: 63-69.

11. Sendova M, Kaiser B, Scalera M, Zhelyaskov V (2010) Della Robbia blue glaze: Micro-Raman temperature study and X-ray fluorescence spectroscopy characterization. J Raman Spectrosc 41: 469-472.

12. Burgio L, Clark RJH (2000) Comparative pigment analysis of six modern Egyptian papyri and an authentic one of the $13^{\text {th }}$ century BC by Raman microscopy other techniques. J Raman Spectrosc 31: 395-401.

13. Burgio L, Clark RJH, Hark RR (2010) Raman microscopy and x-ray fluorescence analysis of pigments on medieval and Renaissance Italian manuscript cuttings. Proc Natl Acad Sci USA, 107: 5726-5731.

14. Manukyan KV, Guerin BJ, Stech EJ, Aprahamian A, Wiescher M et al. (2016) Multiscale X-ray fluorescence mapping complemented by Raman spectroscopy for pigment analysis of a 15th century Breton manuscript. Anal Methods 8: 7696-7701.

15. Gura DT (2016) A Descriptive Catalogue of the Medieval and Renaissance Manuscripts of the University of Notre Dame and Saint Mary's College. Notre Dame: University of Notre Dame Press.

16. Olin JS (2003) Evidence that the Vinland Map is medieval. Anal Chem 75: 6745-6747.

\section{Your next submission with Juniper Publishers will reach you the below assets}

- Quality Editorial service

- Swift Peer Review

- Reprints availability

- E-prints Service

- Manuscript Podcast for convenient understanding

- Global attainment for your research

- Manuscript accessibility in different formats

( Pdf, E-pub, Full Text, Audio)

- Unceasing customer service

Track the below URL for one-step submission https://juniperpublishers.com/online-submission.php 